\title{
Evaluation of Cost and Profit Efficiency of Cowpea Production by using Cost Function / Baghdad Province Case-study
}

\author{
Qays TamiJassamNajah Ali AbidALkarem \\ University of Baghdad-College of Agricultural
}

\begin{abstract}
The deviation of the actual size of production to the optimum size leads to wastage in the use of resources and raising of production costs, then achieve may an inefficiency in production. In other words, farmers do not achieve the appropriate economic sizes. The use of production costs, in the identifying what achieved by production units from economic efficiency, considers one of the most important economic indicators. The aim of the research was to estimate the function of cowpea production and costs to used in the cost and profit efficiency and determination of the optimal sizes. This research adopted a random sample of 80 farmers, representing 3.5\% of the crop growers in Baghdad province. The estimation was done by using the cubic formula which was the most compatible with economic and statistical logic. It was found that the optimal size of the production was 9.01 tons and the higher profit size was 12.6 tons, meaning that $89.7 \%$ of the farmers produced sizes less than optimal size which indicated by the technical efficiency of $45 \%$, the net income at the low costs production level was 11292,48 dinars, the net income achieved at the higher profit production level was 13997.1 dinars, the profitability efficiency of the low costs production level was $69 \%$, the profit efficiency was 29\%, and the area achieving the economic efficiency was 19.12 dunum, while the average of actual area of the sample was 9.7dunum. It was found that most of the farmers planted less of the area that achieved the economic size. The research recommended the necessity of raising cowpea production level and subsidizing production requirements prices and the expansion in the cultivation of this important crop.
\end{abstract}

Keywords: Cost efficiency, optimum size, cowpea crop.

\section{Introduction}

Cowpea is one of the important legume crops, which primarily its grains used as a food for humans [5]. The seeds of it are an important source of protein [10]. The seeds had a higher protein content than the rest of legume crops [12]. The vegetative system, after harvesting, contains a high nutritional value and desirable by livestock [5]. The roots protect the soil from erosion and have the ability to fix nitrogen into the soil [1]. In the country, Baghdad province was in forefront of the country's provinces in terms of production and area planted with the crop, it produced $37 \%$ by about 29296 tons, and the area about $28 \%$ by 14443 dunums [13]. The economic resources and their productivity outputs represented the cornerstone in the agricultural development economics, and the economic use of those resources represented one of the main objectives of economic growth in the agricultural sector [2].rational management requires from producer that aims to achieve the maximum profit works to expand the difference between revenues and costs through increasing the revenues or/and reducing costs. The revenue can be raised by improving the efficiency of productivity to increase production. Reducing costs, in the conditions of perfect competition, gained a great importance where any producer had no essential influence on the market price therefore the opportunities of achieving the profit were the largest by reducing the costs and this requires understanding the nature of the costs and how they contrast with the various levels of production in order to develop criteria to determine the level of production [8]. Among the most important tools, that can be used to increase profits and reduce costs, the development of production techniques through using modern techniques will increase the production amount of the combination of different productive activities appropriate to that environment. It is important to use the standard revenues directly associated with the size of the farm as a function of the average of production costs in the short and long-term [3].

\section{The Research Problem}

The problem of research was in raising the production costs and the farmers didn't achieve production sizes closed to the optimal size of the production and areas then achieved optimal minimization of production costs to the minimum and maximize profits.

The Aims of Research

This research aimed to:

1- Evaluate the costs function of cowpea production in the short-term and determine sizes these achieving minimum costs and maximum profit.

2- Measuring the farms efficiency to achieve high performance rates through the cost and profit efficiency. 


\section{The Research Hypothesis}

The research based on the assumption that the most of farmers do not achieve the optimal sizes of production and area in the actual sizes drifting away from those sizes that achieved the economic efficiency and there was a waste in the using of resources.

\section{The Importance of Research}

The importance of research resulted from the great importance of crop that had a large proportion of farm income for producers of vegetable crops, and the economic importance of estimating production functions which have guidance and economic applications in the agricultural policy that can lead to increase the production if the farmers were guided for the production according to the optimum production rates and optimal use of areas.

\section{Methods And Materials}

The primary data was obtained through a random sample of cowpea growers in Baghdad province according to a special form prepared for this purpose. The sample farmers were 80 farmers represented about $3.5 \%$ of the total growers of the province who were 2750 growers [13]. The data analysis adopted descriptive mathematical and statistical methods. The measurement was conducted viausing Ordinary Least Squares (OLS) which characterized by giving the best unbiased linear evaluation (Blue) of the evaluated economic parameters consonants [7]. The study depended on Statistical Package for the Social Sciences (SPSS) to analyzing data.

\section{Optimal Product}

It is the production that meets the lowest point on an average medium cost curve, it can be evaluated by equaling average cost function with marginal costs function or by differentiating the cost average function and equaling to zero. The optimization acts as an indicator of the appropriate behavior of the farmer to take right economic decisions [4].

\section{profit Maximize Production}

It is the production that meets the equal point of marginal costs with the unit price of the product under the condition that the marginal costs rising.

\section{Technical Efficiency (TE)}

It means producing the greatest possible product with a certain amount of resources, or achieving the same amount of product with minimum amount of resources. It can be evaluated as follows [6]:

\section{$T E=\frac{\text { actual production }}{\text { optimal production }} \times 100$}

The Evaluation of Functions of Cowpea Production Costs

The function of total costs of cowpea production represents the relationship between production quantity and the total costs of production, as follows:

1. Dependent Variable: The total costs values of cowpea production (thousand dinar) were depended on as a dependent variable in the standard models to evaluate costs functions.

2. Independent Variable: The production quantity of cowpea (ton) was depended on as an independent variable in the standard models to evaluate the costs functions. Thus the costs functions were as the following models:

Linear formula $\quad \mathrm{TC}=\mathrm{B}_{0}+\mathrm{B}_{1} \mathrm{Q}$

Quadratic formula $\quad \mathrm{TC}=\mathrm{B}_{0}+\mathrm{B}_{1} \mathrm{Q}+\mathrm{B}_{2} \mathrm{Q}_{2}{ }^{2}$

Cubic formula $\mathrm{TC}=\mathrm{B}_{0}+\mathrm{B}_{1} \mathrm{Q}+\mathrm{B}_{2} \mathrm{Q}_{2}{ }^{2}+\mathrm{B}_{3} \mathrm{Q}_{3}{ }^{3}$

By using SPSS program and OLS method, it was clear that cubic formula was the most correspondent with the economic logic as it passed the statistical and economic tests (Table 1).

Table 1. The evaluated parameters of functions of cowpea production costs

\begin{tabular}{|c|c|c|c|c|}
\hline Variables & Parameters & Evaluates & SE & $\mathrm{T}$ \\
\hline Product & $\mathrm{Q}$ & 1135.98 & 444.25 & $2.557 * *$ \\
\hline Product Square & $\mathrm{Q}^{2}$ & -213.157 & 14.697 & $2.854 * *$ \\
\hline Product Cube & $\mathrm{Q}^{3}$ & 11.902 & 3.332 & $3.572 * *$ \\
\hline Determination Coeff. & $\mathrm{R}^{2}$ & 0.73 & & \\
\hline Adjusted Deter. Coeff. & $\overline{\mathrm{R}}^{2}$ & 0.69 & & \\
\hline Correlation Coeff. & $\mathrm{R}$ & 0.85 & & \\
\hline Model Significance & $\mathrm{F}$ & 22.632 & & \\
\hline Auto Correlation & D.W & 1.646 & & \\
\hline Variance Inflation Factor & VIF & 3.7 & & \\
\hline
\end{tabular}

Source: preparing by researcher according to econometric Statistical Analysis of cost functions . 


\section{Statistical and econometric Analysis}

Based on $\mathrm{t}$-Test, it was clear that calculated $\mathrm{t}$ value of function tendency was higher than $\mathrm{t}$-table where it was significant at $1 \%$ as well as the evaluated function was significant at $1 \%$ according to $\mathrm{F}$ test which was 22.632. The determination coefficient showed that $73 \%$ of total costs vicissitudes were interpreted by the production, while $27 \%$ of these vicissitude belong to another factors that their impacts were absorbed by the random variable and had no place into the model.

The standard tests were conducted to detect the problems of second degree, as follows:

1. The problem of auto correlation was detected using Geary's test which is non-parameter test used to test the random of RUNS, as follows [7]:

$\mathrm{E}(\mathrm{R})=\frac{2 \mathrm{~N}_{1} N_{2}}{\mathrm{~N}}+1$

$\mathrm{SR}=\frac{2 \mathrm{~N}_{1} \mathrm{~N}_{2}\left(2 \mathrm{~N}_{1} \mathrm{~N}_{2}-\mathrm{N}\right)}{\mathrm{N}^{2}(\mathrm{~N}-1)}$

Whereas N: the total No. of observations, $\mathrm{N}_{1}$ : the number of positive signs of the residuals, and $\mathrm{N}_{2}$ : the number of negative signs of the residuals.

Prob. $[\mathrm{E}(\mathrm{R})-1.96 \delta \mathrm{R} \leq \mathrm{R} \leq \mathrm{E}(\mathrm{R})+1.96 \delta \mathrm{R}]=0.95$

Prob. $[15-1.96(2.5) \leq 8 \leq 15+1.96(2.5) 10.1 \leq 8 \leq 19.9$

As long as R is located in a period of confidence, we do not reject the null hypothesis at $5 \%$, which recognizes that the results of successive residuals not depending on each other [7].

2. Park test was used to detect instability of the homogeneity of variance(Hetroscedasticity ). The model was found free of this problem due to the equation was not statistically significant, as shown by the test follows:

Linui $=12.861-0.316 \mathrm{Q}$

$\mathrm{t}=(17.24) \quad(0.599)$

$R^{2}=0.024 \quad F=0.359$

3. The problem of multiple linear correlation(multicolinearty ): there was no linear relationship among independent variables due to the model was non-linear in terms of the variables $\mathrm{Q}^{2}$ and $\mathrm{Q}^{3}$ were correlated with the variable $\mathrm{Q}$, but the relationship was non-linear [7].

\section{Determination of the Optimal SizeofProductionand Technical Efficiency}

It can obtained the optimal rate of the low-cost production by derivation the average of the total cost from the total cost equation by dividing the farmer to the product, after excluding the consonant limit because it reflects the fixed costs, the equation of the total cost average of cowpea as follows:

$\mathrm{TC}=136.893+1135.9 \mathrm{Q}-213.157 \mathrm{Q}+11.902 \mathrm{Q}$

$\mathrm{AC}=\frac{136.893}{Q}+1135.9-213.157 \mathrm{Q}+11.902 \mathrm{Q}^{2}$

In order to determine the optimal production that minimizing the costs, the first condition that necessary to minimize the function was applied by taking the first derivative of the total cost average function of the product and equality to zero and then solve the equation for $\mathrm{Q}$ as follows:

$\left.\frac{\partial \mathrm{AC}}{\partial \mathrm{Q}}=(-136.893) / Q^{2}\right)-213.157+23.804 \mathrm{Q}$

$\mathrm{Q}=9.01 \mathrm{tons}$

The actual production, achieved at the sample level, was 4.12 tons, i.e. less than production that minimizing cost which was 9.01 tones and only $10.3 \%$ of the farmers produced higher than the optimal size or in other words 89.7 of farmers producing sizes less than optimal size and this was indicated by the technical efficiency which was 0.45 and it indicates the production deviation from the optimal minimum cost production.

\section{Elasticity of Cost (E)}

The elasticity of costs was calculated by dividing the Marginal Costs (MC) to Average Cost (AC) with compensation the average sample production [11] which was 4.12 tons.

$$
\begin{aligned}
& \mathrm{E}=\frac{M C}{A C} \\
& \mathrm{EC}=\frac{1135-426.31 \mathrm{Q}+35.7 \mathrm{Q}^{2}}{\frac{135.893}{\mathrm{Q}}+1135.9-213.157 \mathrm{Q}+11.902 \mathrm{Q}^{2}}
\end{aligned}
$$

The elasticity of cost was 0.034 , which means that the increasing of production by $10 \%$ would lead to increasing costs by $3 \%$ i.e. these farms had large economies capacity through which its activities can be expanded to raise productivity to reach optimal minimum cost size at the elasticity value which equals to one.

\section{Evaluation of the maximizing profit production size}

The average of the sale price in the study area was 1450 thousand dinars/ton oscillating between the upper limit of 2 million dinars/ton and a minimum limit of 750 thousand dinars/ton.

$\mathrm{MC}=\mathrm{P}$

$1135.98-426.314 Q+35.7 Q^{2}=1450$ 
Depending on the quadratic equation, it was clear that the maximizing profit production size was 12.6 tons, at an estimated value of 18250 thousand dinars based on the prevailing price in the study area and to ensure the validity of the results obtained:

$\Pi=\mathrm{TR}-\mathrm{TC}$

$\Pi=1450 \mathrm{Q}-\left(1135 \mathrm{Q}-213.157 \mathrm{Q}^{2}+11.9 \mathrm{Q}^{3}\right)$

$\Pi=314.02 \mathrm{Q}+213 \mathrm{Q}^{2}-11.9 \mathrm{Q}^{3}$

$\frac{\partial \pi}{\partial Q}=314.02+426.31 \mathrm{Q}-35.7 \mathrm{Q}^{2}$

$\frac{\partial^{2} \pi}{\partial^{2} Q}=426.31-71.4 Q=0$

When compensating the value of maximizing profit production level in the equation above, it was clear that the second derivative took a negative value which represented the great end of the profit function.

Cost Efficiency

Costs efficiency was 1.09 which is a reflection of decreasing costs at the optimal size, that means the costs at the actual level of production were less than those at the size which minimizing costs size which interpreted that farmers achieved maximum efficiency if they could reach the optimal size of production as much as the costs [8].

$\mathrm{CE}=\frac{1772}{1617}=1.09$

\section{The Net Income Achieved at the Actual Production, Minimizing Costs and Maximizing Profit}

Net income depends on possible levels of price and there are price levels do not allow for the producer to carry out the production and there are other price levels allow to reduce losses and others allow to achieve a profit [3]. Consequently, there are several possible probabilities ranging from stop production to achieve economic profit over the costs all. It can be noted that the availability of the first condition which is equal to marginal returns with marginal costs by using the profit equation. Net income was estimated at actual minimizing costs production and maximizing profit at that 4.12, 9.01 and 12.6 tons, respectively, and are as follows:

$\Pi=\mathrm{TR}-\mathrm{TC}$

$\Pi=\mathrm{P} . \mathrm{a}-\mathrm{TC}$

$\Pi=1450 \mathrm{Q}-\left(136.893+1135.98 \mathrm{Q}-213.157 \mathrm{Q}^{2}+11.9 \mathrm{Q}^{3}\right)$

With compensating the production amounts at the mentioned levels in $\mathrm{Q}$ we could obtain the net income of 4081 dinars at the actual production level, thus it less by 7210.52 dinars than the net income achieved at minimizing costs production level which was of 11292.48 dinars, while we note that the net income achieved at the maximizing profit production level which was 13997.1 dinars, which was higher than the other achieved at the actual size by 9896.9 dinars. Also, it can be noted that the average of costs decreased at the minimizing size by 182.6 dinars which is attributed to the product expansion on the one hand, and on the other side the product was able to obtain an increment in production with maintaining no increasing in costs, thus achieved the economic efficiency condition as it obtained increment in the production with minimum costs at the optimal size.

\section{Profit Efficiency}

Profit efficiency had been estimated to detect which productive level had a profitability protection. It was found that the minimizing cost production level was the best which was 6.9 and indicating that it was more efficient compared to others, and we noted that the efficiency of the profit reached 0.29 .

\section{Evaluation of Optimal Area}

Individual establishment, under perfect competition, operates at optimal capacity and runs this capacity at a rate of an optimal product. In the case of competition, sufficient number of farms available to the extent that the firm alone cannot influence the price of the commodity in the market and in this case the establishment had to work at the optimal capacity of the project or run it at the rate of the optimal product and then achieved the maximum economic efficiency, or in other words, commodity was produced by lower possible cost [4]. Because it's hard for farmers working at optimal sizes for the reasons mentioned in the theoretical framework, an optimal area that achieved an economic efficiency was estimated through a regression between the area as a dependent variable and the production as independent variable:

$\mathrm{A}=\mathrm{B}_{0}+\mathrm{B}_{1} \mathrm{Q}$

$\mathrm{A}=1.388+1.968 \mathrm{Q}$

$\mathrm{t}=(0.587) \quad(4.437)$

$\mathrm{R}^{2}=0.43 \quad \mathrm{R}^{2}=0.40 \quad \mathrm{~F}=19.687 \quad$ D. $\mathrm{W}=1.143$

With compensating minimizing costs size in the Q, the area achieved the economic efficiency of 19.12 dunum, while the actual average area based on the sample level was 9.7 dunum. Thus, farmers had to expand in cowpea crop area to get the optimal size of the production and benefit from the advantages of the great production, which can only achieve with large area noting that $83 \%$ of the crop growers producing in the area less than optimal. Thus, the area must be provided to be capable accommodating specialized in work that leads

DOI: $10.9790 / 2380-1004014448 \quad$ www.iosrjournals.org $\quad 47 \mid$ Page


to increment in the production compared with the ratio of the using resources which capable at the same time to reduce production costs. The size of the area at the maximizing profit production was 26.1 dunum and most of farmers producing under this ranges of area.

Table 2. The economic indicators of cowpea producers

\begin{tabular}{|c|c|c|c|}
\hline Variables & $\begin{array}{r}\text { Actual Production } \\
\text { level }\end{array}$ & Optimal Production & $\begin{array}{r}\text { Profit Maximizing } \\
\text { Production }\end{array}$ \\
\hline Production (ton) & 4.12 & 9.01 & 12.6 \\
\hline Revenues (thousand dinars) & 5974 & 12905 & 18270 \\
\hline Total cost (thousand dinars) & 1893 & 1617 & 4272.9 \\
\hline $\begin{array}{lrr}\text { Net } & \text { income } & \begin{array}{r}\text { thousand } \\
\text { dinars })\end{array} \\
\end{array}$ & 4081 & 11288 & 13997.1 \\
\hline Profitability Efficiency & 2.2 & 6.9 & 3.2 \\
\hline Costs Elasticity & 0.034 & 1 & 4.2 \\
\hline Area (dunum) & 9.7 & 19.01 & 26.18 \\
\hline
\end{tabular}

Source: preparing by the researchers depending on the cost function and the profit function and the questionare.

\section{Conclusions}

The researcher found that most farmers planted less than an optimal area that achieving the optimal economic size and there was a waste in the use of available resources which made the optimal production less than that which minimizing the cost.

\section{Recommendations}

- Necessity to improve the productivity of cowpea crop by following the technical recommendations related with the use of fertilizers and their amounts and use of seeds recommended by the relevant departments.

- Support the price of production requirements to work on reducing total costs, this would leads to increasing farm income by the expansion of cowpea cultivation and thereby achieve the optimal economic efficiency.

- The expansion of cowpea cultivation which is economically important and reaching the optimal area that recommended by this study and previous studies to achieve the economic efficiency to meet the optimal size of the production.

- Necessity of policies to be guided towards investment in the production of new varieties of seeds and the use of modern irrigation techniques in order to increase production to reach the optimal production size.

\section{References}

[1] Aziz, E. E., N. Gad and N. M. Badran. 2007. Effect of cobalt and nickel on plant growth, yield and flavonoids content of Hibiscus sabdariffa L. Australian Journal of Basic and Applied Sciences. 1 (2) : 73-78

[2] Ali,M,H. Eskendr,H.Najah, A.2011. Economic efficiency of barley farms in Diyala province. Journal of administration and Economics.vol (34) 95 :p 44-51.

[3] Adinya, I. B. 2009. Analysis of costs - Returns Profitability in Groundnut marketing in Bekwarra Local Government Area cross River state, Nigeria. The Jo. Of Anwal\& Plant sciences 19(4):212-216.

[4] AL-Ezy ,J ,M ,H.2002. . The possibility of achieving economic objectives on small farms. The Iraqi Journal of Agricultural Sciences 33 (6) p:245-251

[5] AL-SahafF.H, M.Z.K. AlMhariband A.H. Mahmood.2012. Response of Cowpea to application methods and Cobalt concentration. The Iraqi journ-al of agricultural science, 43(6):53-58.

[6] Douglas, B. B. and M. D. Whiwston. 2008. Microeconomics, McGraw hill PP: 268.

[7] Gujrati, N. D. 2004. Basic Econometrics. McGraw Hill Co. Press. LTD. P: 405.

[8] M.A.Ferhan and Mohameed J.Ali.2012.An Estimation of Cost Function and size Economies of BabilGovernorate as case Study , Iraqi journal of agricultural science 43(2):47-56

[9] Omonona, B. T., Egbetokum, O. A. and Akanbi, A. T. 2010. Farmers Resource use and Technical Efficiency in Cowpea production in Nigeria . Economic Analy-sis \& Policy, Vol 40. No.1, P: 87 - 97.

[10] Radhi D. Al-Assafi,2012, Effect of Phosphor us on Improving Yield and its components of Cowpea selected by Honeycomb. The Iraqi Journal of Agricultural Sciences 41 (6):21-28 .

[11] Raheem. K. H.2011, Analytical study to estimate the cost functions productivity and optimal size of the fish farms in the province of Babylon in 2010.theDiyala journal of science Agricultural, 100 - 93 : ( 1 ) 3.

[12] Simmonds,N.W .1979 .Principles Of Crops Improvments.3rd ed., Longm-an,London,U.K.pp:408.www. ocs.org 